\title{
LINGUISTICS
}

UDC $811.111-26$

DOI: $10.17223 / 24109266 / 7 / 1$

\section{WHEN LANGUAGES COLLABORATE: \\ NOVEL AND SCREEN VERSION MULTILINGUAL STRUCTURE ("THE DA VINCI CODE" BY DAN BROWN)}

\author{
Yu.M. Alunina, N.E. Nikonova \\ Tomsk State University (Tomsk, Russia). \\ E-mail: alyunina.y@mail.ru; nikonat2002@yandex.ru
}

\begin{abstract}
This article covers the issue of foreign languages interrelation of "The Da Vinci Code" (2003) novel by Dan Brown and the screen version (2006) by Ron Howard, their functions, usage and screen representation peculiarities. Audio cinema narration is researched in the context of multilingualism, due to its importance as one of the most significant components for postmodern poetics of the game-novel, representing abstracts and remarks in French, Spanish and Latin on the main English language sounding background in the original. The most interesting feature of the novel audio code is its diverse multilingual structure. This work presents the result of comparative-contrastive analysis of the novel and the movie for the first time. The article covers the sounding text realization issue in the literary work, language collaboration functions and the screen representation strategies.
\end{abstract}

Keywords:

\section{Introduction}

"The Da Vinci Code" by D. Brown belongs to the genre of game-novels, common in postmodern literature, due to its synthetic nature. The text is an instrument of expression of cultural elements (painting, sculpture, literature, music, etc.), in connection with which we can talk about deep intermedial analysis. A screen adaptation of "The Da Vinci Code" is considered a variant of a work of art, embodied on the screen by means of cinema. One of the productive cognitive techniques found by the director is the introduction of the multilingualism phenomenon to the narrative film structure.

The target material of the current work is "The Da Vinci Code" novel and its screen version, both in the original. Within the study there were used such research methods as comparative-contrastive literature and cinematographic analysis, linguistic analysis, situational and culturalphilosophical analysis. From the practical point of view, the results of this work could be applied to multilingualism study in modern culture; theory of literary, screen adaptation and movie translation 


\section{Methodology}

In post-modern philosophy, text is viewed as a collage of cultural and semiotic codes. In the context of intermedia, such codes are formed by the use of ecphrases - material cultural objects. A part of a literary work, ecphrases are symbols or mediums, by which the author creates a mosaic structure of the text, which is the leading feature of a post-modern work of art. In "The Da Vinci Code" novel and its screen version, the mosaic structure of the narrative is clearly seen on the level of language implementation. Language can also be considered as a code constituting the canvas text written and sounded. The expressiveness of such code is enhanced with multilingualism and lies in several languages combining. A multilingual canvas of the analysed work can be viewed as a vast palette of language situations that unite its members with a communicative intention. In the work "The Post-modern Condition" (1979), the author JeanFrançois Lyotard (1924-1998), literary theorist and philosopher from France, cites the opinion of the Austrian scientist Ludwig Josef Johann Wittgenstein (1889-1951), who was engaged in the study of the philosophy of language. Wittgenstein, who studied the modes of discourse, "...language games" [1]. This term refers to certain limits, within which statements are subject to given context rules. Lyotard explains this by saying that "every utterance should be thought of as a 'move' in a game" [Ibid], which is done in order to achieve a certain goal. So it seems logical to conclude that "The Da Vinci Code", belonging to the genre of the game-novel, complicates its own intermedial code at the linguistic level also. Here every language, being a self-semiotic system, sets the framework within which the statements are realized on foreign (relative to the original book) languages: French, Spanish, Latin. Switching from one language to another brings an aesthetic function and creates multi-discourse space into novels and cinematic narrative.

Multi-discourse structure in "The Da Vinci Code" is manifested in the interaction of foreign languages in the speech of the characters, as far as "the use of multiple linguistic codes in films may convey different functions" [2]. Multi-discourse penetrates into all of the other layers of text generated by audio and visual codes in the novel and its film version [3]. Symbolically they can be divided into film, audio and text codes. They are all interrelated and complementary, but the main role is played by the elements of the text, through which the variety of linguistic code is embodied. In the literary embodiment of "The Da Vinci Code", there are extracts in French, Spanish and Latin.

According to the conception of Dionysios Kapsaskis, University of Roehampton (UK) professor, presented in a review on O'Sullivan's book, "foreign languages have played a key role in the development of film and 
that they have been negotiated through complex and diverse translational processes. ...each of the translation strategies used to manage linguistic difference in cinema has had discernible aesthetic and ethical impact on the way otherness is represented" [4]. So, we can say that multilingualism and a film are very interconnected in functional point of fact, as far as they were developing simultaneously: cinematography produced a cinematographic art; multilingualism became an integral part of this art language.

\section{Discussion of Results}

In the analyzed screen version, foreign languages are a means of incorporating different linguacultural ciphers and complicating semiotic space of culture. On the screen, a foreign language acts as cultural code. The use of different languages for sounding of text focuses not only on the demonstration of national identity, but also aims to show the variability of the encoding. Living and dead languages, and processing communication between the characters, become the instruments of encoding and decoding of the information transmitted.

\section{French language}

French surpasses other foreign languages, as implemented mainly in the dialogues of the French. In the novel, unlike in the film version, French is rare. As a rule, these are individual words or phrases that appear in the flow of the English-language speech, for example, Professor Langdon's French terms to explain the meaning of symbols. Some French words also appear in the author's speech. Thus in the book, there are 128 fragments in French: among them 41 are author phrases; 32 are found in the replicas of the supporting characters (the butler Remy Legaludec, the guard of the Louvre, the night keeper of the bank, the night manager of the bank, the policemen, the taxi driver, etc.); 32 belong to Sophie Neveu; 9 to Bezu Fache; 7 to Collet and to Lee Teabing; and 6 to Robert Langdon. In the original version of the work, none of the mentioned fragments is accompanied by a footnote or a comment at the end of the book, setting the intersemiotic intention. The only thing that distinguishes the text visually is itsitalic font.

The motion picture is replete with French speech. All dialogues, when only the French speak, are implemented in their native language. In the film, the French sounds 41 times, revealing the director's desire to strengthen the incorporated intersemiotic potential in Brown's text and marking it by the language code change that indicates the transition to a different discursive and linguacultural plane. Extended French dialogues are realized among representatives of law enforcement agencies in Paris: police, security 
service. When in the picture area there are characters present who are not native French speakers, the conversation is conducted in English. The dialogues' text added into the film in a foreign language does not create a barrier for understanding, due to the subtitles provided.

Besides the dialogues, in the film version of the novel there are flashback pictures in French devoted to the recollections of Sophie's past, in particular, about her life and relationship with Jacques Sauniere. In this way, Sophie recollects in French the death of her parents and younger brother (01:01:53-01:02:09). (Hereinafter referred to the elapsed time in "The Da Vinci Code" movie.) This text, like a voice-over, can be identified as an internal or monologuous discourse, since it is revealed only in the mind of the character and appears to the audience in a retrospective view. However, the Francophone implementation of such memories in the film does not correspond to the author's intention. According to Brown's version, between the granddaughter and her grandfather there was an agreement to communicate in English, exclusively, at home: "French at school. English at home" [5].

In some cases in the screen version, there appear fragments in French which do not exist in the novel, even in English, for example, the conversation between Bezu Fache and Sophie Neveu, at their first meeting (00:16:0200:16:15) when she asked Professor Robert Langdon to call to the US Embassy allegedly, and she was meanwhile distracting the police captain. However, in the film, there are also phrases that repeat those existing in the novel: "Ce n'est pas le moment!" [Ibid] (00:16:01), - as well as phrases with minor changes: the sentence 'Excusez-moi, messieurs" [Ibid] in the book referred to as "Excusez-moi, commissaire" (00:15:55) in the movie and in the novel phrase "Bonjour, vous êtes bien chez Sophie Neveu. ...Je suis absente pour le moment, mais..." [Ibid] contains only the first sentence in the film (00:16:52-00:16:53). This compression can be explained by the natural conditions of the implementation of sounded text to space in the movie.

\section{Spanish language}

There are only 5 Spanish expressions in the novel. These are capacious enough characters' phrases. Spanish outlines the narrow circle of his carrier, marking the nationality of the heroes.

Firstly, Spanish is spoken by Bishop Aringarosa from Madrid and by Opus Dei Monk Silas. We can say that for them it is a common language, not only in its linguistic and communicative aspects, but also in terms of common ground in the context of the novel plot problems. In the novel, Aringarosa refers to Silas in Spanish only once: when the latter does not remember his name, the Bishop responds "no hay problema" [Ibid] and offers him to be called Silas. This is the only case where we can talk about 
the implementation of the communicative function of the Spanish language in the novel, though the answer to the question was in English (original). In the chronology of the monk's life, it is the last precedent to communicate with someone in their native language. After this phrase and with the new name acquisition, Silas closed the path to his past, which from that moment is only a bad memory.

Secondly, the identifying language function can be judged by the use of Spanish speech in intrapersonal communication. Silas's detachment from all social institutions is represented in the novel in Spanish: the family (father denies his son in Spanish - "Tu eres un desastre. Un espectro" [5]), prison (the prisoners mock Silas in Spanish: "Mira el espectro" [Ibid]). In the description of the last hero, Brown also adds a phrase in Spanish, which is not pronounced out loud but in the mind of the character: "Yo soy un espectro... palido como un fantasma... caminado este mundo a soas" [Ibid]. This expression shows Silas being lost in the human world and the realization of his uselessness. Later, Silas, finding himself in the service of God says "Hago la obra de Dios" [Ibid].

In the screen version, Spanish language is presented three times. It appears twice in the flashbacks devoted to Silas's past, where Aringarosa (a priest at that time) pronounces short phrases when the temple is robbed and the priest is attacked. In the novel, this text is absent, and the movie has the subtitles in English ("Stealing in a house of God!" [00:36:08]), so the ear can determine that there sounds the verb "ladronear" (to steal) and the combination "casa de Diós" (a house of God). Further, when Silas comes to rescue Aringarosa, the latter calls him an angel ("You are an angel" [00:36:25]), which is also not written in the subtitles in Spanish, and can only be heard - "eres un ángel".

Silas himself utters only one sentence in the film version, perceived by ear in the process of analyzing the film as "soy un fantasma" and recorded in the original subtitle as "I am a ghost" [02:10:04].

Director's strategy follows the author's idea to maintain the proximity between Silas and Aringarosa. Howard's innovation is the creation of the socalled framework composition for showing the monk's fate: before meeting Aringarosa, as he in Spanish fancied himself a lonely ghost; he in Spanish called himself a servant of God, now dying; and as to coming to God, he calls himself a ghost again.

\section{Latin language}

Third linguistic-semiotic space is included in the screen version by an ample use of words, phrases and expressions in Latin.

According to Brown, Latin is not used in communications; in the book there are only cases of certain lexical items' use which perform the function 
close to the metalinguistic or nominative one. It lies in the fact that the novel characters explain certain contextual realities by the use of terms in Latin, for example, sub rosa, cruciare, PHI [5]. In the film adaptation there is only the first combination [1:44:45], but Howard's movie characters, unlike in the novel, carry on complete dialogues and monologues in Latin.

The motion picture shows three telephone conversations with "the teacher" / One of them is with Silas [00:06:51-00:07:40] and the other two are with Manuel Aringarosa [00:14:05-00:14:22] and [1:52:12-01:52:27].

In the first case, the selection of the dead language for the phone call can be explained by the director's desire to create a special role of the protagonist. For Silas, the sense of life is in serving God; therefore, the monk perceives "the teacher" as his messenger. Silas has never seen "the teacher", though he unconditionally believes in its credibility, if not of his divine origin. In Latin there opens the soul of the monk, his inner world and experiences, because, in the same language, he turns to God in prayer, sincerely asking for forgiveness for their sins ("In nomine Patris, et Filii, et Spiritus Sancti" [00:08:35-00:08:53]), praying for a place for his victim (Sandrine's) soul, a sister of the Church of Saint-Sulpice, Paris [00:46:5000:46:55].

In the film adaptation, flashbacks can be traced to a Latin phrase, which literally repeats the text from the book: "Castigo corpus meum" [Ibid] [00:58:15-00:59:02]. In this Latin language embodiment, there appeared Silas's aspiration to join the sacred culture. Despite the fact that Silas considers himself a servant of God, his belonging to the church can be called only formal, because of his misunderstanding of the true meaning of worship and the church's role.

Another character, knowing the Latin language, is Manuel Aringarosa. For the first time in the movie, he speaks Latin when in the presence of a journalist he received a phone call from "the teacher". To prevent the spread of the information not intended for simple layman, the bishop replies to his interlocutor in Latin, building a language barrier between those initiated into the secret and those who are considered unworthy to know it. If we put the mystery of the Holy Grail to a special type of culture, to the heritage of the church, we can give the cultural language function to the Latin.

On the other hand, the identifiable function is also obvious, Latin, like Spanish, unites Manuel Aringarosa and Silas based on the secrecy of the Grail idea community. Spanish, a living language, is used as a marker of the past, while Latin, a dead language, is used to mark the present. With regard to Silas, this could be another feature of his psychological portrait. His soul died with the mother tongue and the name given him at birth. Only in the end of the film can we talk about the union of the physical and the spiritual, when Silas - it is the only time in the film - says a phrase in Spanish, calling himself a ghost. 
Thus, we can conclude that the Latin language is spoken by the clerical circles and by those seeking to get into them. This is a unique marker of the characters belonging to a secret society and to the field of the chosen in the context of the storyline. Latin also functions as a tool for forming a religious discourse, a kind of barrier for the uninitiated into the secret, and the channel through which they can penetrate into its essence.

\section{Conclusion}

From an aesthetic point of view, the language switching function is to create an effect of switching and changing the linguacultural code, to form a space-semiotic barrier separating from the base sounded text and at the same time, a special link with it. On the one hand, Latin, a dead language, appears when they want to hide certain information from prying ears - to encode it. On the other hand, due to foreign languages in the film, they decode not only text puzzles, but also explain other elements of film narration given by material ecphrases. Therefore, a written and a pronounced word in its multilingual incarnation become the centripetal force making the story move along the desired trajectory. Thanks to this, the multidimensionality poetics of the game-novel gets its embodiment in the plane of mass culture, as well as on the intellectually challenging level.

An important role is given to French and Spanish languages in flashbacks, becoming a mirror of the characters' souls, to which these languages are native (Sophie and Silas). In flashbacks are shown their intimate emotional experiences, about which no one else knows.

From the linguistic point of view, foreign languages in the novel and film "The Da Vinci Code" perform the identification, communication, metalinguistic and nominative functions, depending on the context presented.

The film's multilingualism makes the sound cover equally extensive in its complexity to the intertextual and visual representation of the text on the screen. In addition, the technique in the analyzed film is intended to focus on the nature of the plot peripeteia - comprehensive and universal - in terms of both space and time. This is another means to focus on viewer involvement in literary and cinema works, into the text game, and it coursesthrough all the artistic world canvas of postmodernism. This director's overture shows the multidimensionality of the language system, changing the use of linear canon of the speech flow reproduction.

\section{References}

1. Lyotard, J.F. (1984) The Postmodern Condition: A Report on Knowledge. 111. Minnesota. Available from: http://perpustakaan.bpn.go.id/e-library/Digital\%20Documents/Koleksi_ 5472.pdf (Accessed: 02.03.2016). 
2. Bogucki, L. (2015) Accessing Audiovisual Translation. 216. Frankfurt am Mein.

3. Howard, R. (2008) The Da Vinci Code. DVD. Ekaterinburg: Uralskiy Elektronnyiy zavod. (Russian, English track).

4. Kapsaskis, D. (2014) Carol O'Sullivan (2011). Translating Popular Film. The Journal of Specialized Translation. Available from: http://www.jostrans.org/issue21/rev_osullivan.pdf (Accessed: 01.02.2016).

5. Brown, D. (2009) The Da Vinci Code. 590. London.

Information about the authors:

Alyunina Julia M., Student, Department of English Philology, Faculty of Foreign Languages, Tomsk State University (Tomsk, Russia).E-mail: alyunina.y@mail.ru

Nikonova Natalia E., Ph.D., Head of Department, Department of Romance and Germanic Philology,

Faculty of Philology, Tomsk State University (Tomsk, Russia). E-mail: nikonat2002@yandex.ru 